SCIENTIFIC REPORT

\title{
Genotypic and phenotypic heterogeneity in familial microcoria
}

\author{
F D Bremner, H Houlden, S E Smith
}

Br J Ophthalmol 2004;88:469-473. doi: 10.1136/bjo.2003.027169

Aims: To describe the clinical features and genetic findings in two families presenting with microcoria inherited as an autosomal dominant trait.

Methods: Both affected and unaffected members of two families displaying familial microcoria were examined. Flash photography or infrared pupillography were used to assess pupils, and a full ophthalmic examination including visual acuity and field testing, refraction, biomicroscopy of anterior and posterior segments, and measurement of intraocular pressure were performed. DNA from the blood of affected and unaffected family members was investigated using standard markers to look for a possible gene defect in the chromosome 13q31-q32 region.

Results: All affected members of both families had pinpoint pupils which responded normally to light and accommodation. None of these subjects exhibited any other ocular abnormality. The iris of affected members showed stromal thinning and apparent absence of the iris dilator muscle in the first family, but was smooth and lacked all trabecular structure in the second family. The microcoria was present at birth in the first family but developed progressively at a later age in the second family. Haplotype analysis suggested the gene defect is not located in the chromosome 13q31-q32 region in the first family but the evidence was not conclusive in the second family.

Conclusion: Although both families presented with similar pupil abnormalities inherited as an autosomal dominant trait, they show important phenotypic and genotypic differences suggesting that this is a heterogeneous condition. The possible mechanisms underlying the microcoria are discussed.
$F$ amilial microcoria is a rare disorder usually inherited as an autosomal dominant trait, ${ }^{1-9}$ although two instances of recessive inheritance have been reported..$^{410}$ The pupil abnormality usually occurs as an isolated congenital abnormality associated with failure of development, ${ }^{11}$ absence, ${ }^{12-13}$ or fibrosis $^{14}$ of the dilator pupillae muscle. In some instances there is also goniodysgenesis ${ }^{5-7} 9^{15}$ or a persistent pupillary membrane. ${ }^{16}$

There is only one genetic study of familial microcoria in the literature. ${ }^{17}$ Linkage analysis in a large French pedigree ${ }^{3}$ indicated that the gene is located on the long arm of chromosome 13 (13q31-q32). In this paper we report pupillographic and genetic studies in two new families with inherited microcoria; our results suggest there may be both genotypic and phenotypic heterogeneity in this condition.

\section{SUBJECTS AND METHODS}

\section{Families and subjects}

Family A (fig 1) is of British white origin. The proband (III.5) is a healthy male aged 35 with microcoria since birth. His only complaint is of nyctalopia. There are two other affected family members. The general health of all examined family members was good (apart from subject III.3 who is disabled with cerebellar ataxia), and none was taking drugs that affect the pupil.

Family B (fig 2) is Afro-Caribbean. The proband (III.2) is a healthy myope aged 31 referred because her optometrist could not obtain adequate retinoscopy (not a problem at previous visits). She reported that up until adolescence her pupils were normal in size but from age 18 they had started to become smaller. Her mother (II.2) and deceased maternal grandfather had a similar history. She has no visual symptoms. The other examined family members are all in good health and take no medication that affects the pupil.
Family A

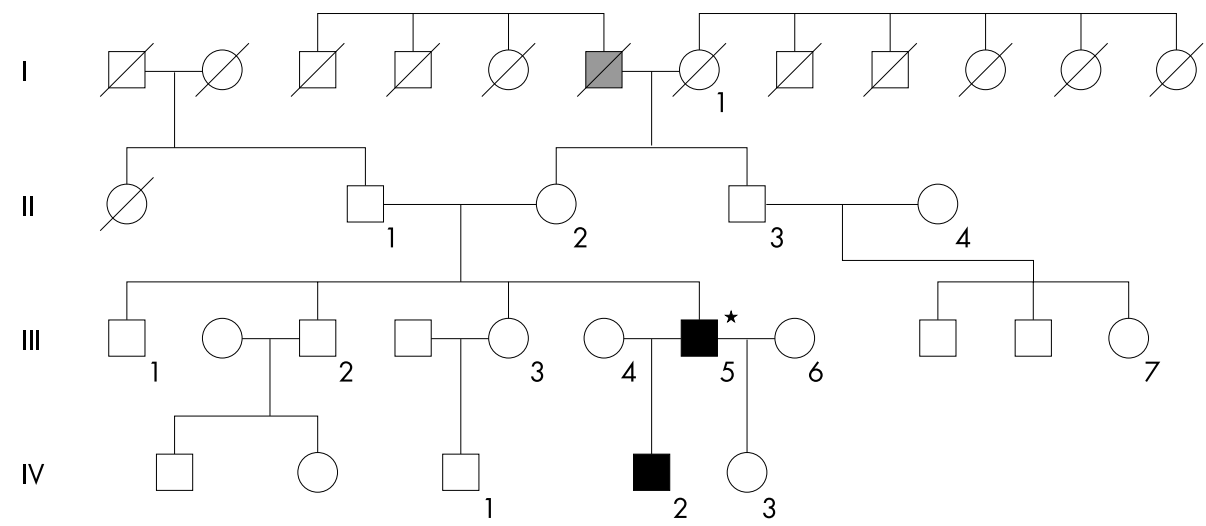

Figure 1 Pedigree of Family A. The proband is indicated by an asterisk. Subjects that were available to be examined in this study are numbered. Filled in symbols indicate affected family members, grey symbol indicates "probably affected" individual (unavailable for examination), clear symbols indicate unaffected family members. The proband's mother (II.2) showed similar iris abnormalities to other affected family members but her pupil diameters lay just within the normal limits when compared with age matched control subjects. 
Family B

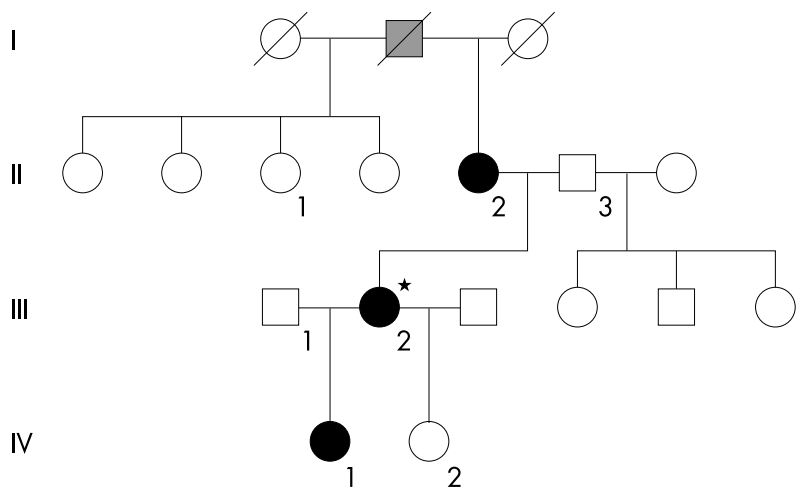

Figure 2 Pedigree of family B. The proband is indicated by an asterisk. Subjects that were available to be examined in this study are numbered. Filled in symbols indicate affected family members, grey symbol indicates "probably affected" individual (unavailable for examination), clear symbols indicate unaffected family members.

\section{PUPIL MEASUREMENTS}

Pupil measurements were made in darkness using an Applied Science infrared TV pupillometer. ${ }^{18}$ In six subjects conventional pupillography was not possible, and pupil measurements were performed photographically with room lights on. Pupillographic measurements were compared with normal data obtained from age matched healthy control subjects $(n=267)$.

\section{Genetics}

Ethics approval was obtained from The National Hospital for Neurology and Neurosurgery and the Mayo Clinic Jacksonville to carry out genetic studies. Consent was obtained in all individuals to participate in this research. DNA was extracted from blood by the standard phenol/ chloroform extraction method. To examine the region chromosome 13q31-q32 (between $67.65 \mathrm{cM}$ and $75.19 \mathrm{cM}$ ) we employed the following markers: D13S175, D13S217, D13S218, D13S153, D13S156, D13S263, D13S170, D13S265, D13159, D13S158, and D13S173. Each fluorescent labelled microsatellite repeat marker was amplified using the following method: $25 \mathrm{ng}$ of DNA was used in a $50 \mu \mathrm{l}$ reaction mixture containing $20 \mathrm{pmol}$ of each primer, $0.2 \mathrm{mM}$ dNTPs, 0.5 unit of Taq Gold polymerase (Perkin Elmer), $1.5 \mathrm{mM}$ $\mathrm{MgCl}_{2}, 75 \mathrm{mM}$ Tris-HCL, pH 9.0, $20 \mathrm{mM}\left(\mathrm{NH}_{4}\right)_{2} \mathrm{SO}_{4}$, and $0.01 \%$ Tween-20. Polymerase chain reaction was performed on a Perkin-Elmer 9700 thermal Cycler (Perkin Elmer, Applied Biosystems, Foster City, CA, USA). The cycling consisted of denaturation at $94^{\circ} \mathrm{C}$ for 15 minutes, followed by 25 cycles of $94^{\circ} \mathrm{C}$ for 30 seconds, $60^{\circ} \mathrm{C}$ to $50^{\circ} \mathrm{C}$ touching down protocol for 30 seconds, and $72^{\circ} \mathrm{C}$ for 30 seconds. After that, 12 cycles of constant annealing temperature at $50^{\circ} \mathrm{C}$ and a final amplification at $72^{\circ} \mathrm{C}$ for 10 minutes were carried out. Polymerase chain reaction fragments were checked on a $1 \%$ agarose gel. All samples were genotyped for the dinucleotide repeat by analysis on the ABI377 using the Genescan analysis package and the Genotyper software program (Perkin Elmer) to identify alleles.

\section{RESULTS}

Pupil diameters, light, and near responses for both families are given in table 1 .

\section{Family A}

The proband (III.5) had pinpoint pupils (diameters $<2 \mathrm{~mm}$ ) which reacted normally to light or an accommodative effort. Slit lamp examination showed markedly abnormal irides with stromal thinning peripheral to the collarette, baring of the underlying pigment epithelium but no full thickness defects allowing transillumination. The pupil margins, iris root, anterior chamber angle and depth were all clinically normal and the intraocular pressures were $16 \mathrm{~mm} \mathrm{Hg}$ in both eyes. With a small hypermetropic correction his visual acuities and colour vision were normal but Goldmann kinetic perimetry confirmed mild constriction of the visual fields under mesopic conditions $\left(10^{\circ}\right.$ loss to $14 \mathrm{e}$ target in all meridians compared with normal subjects ${ }^{19}$ ).

The proband's son (IV2) had similar microcoria with preserved light and near responses and abnormal irides (fig 3A). The proband's mother (II.2) had pupils of normal diameter for her age, but slit lamp examination showed iris stromal abnormalities similar to the proband (fig 3B). She reported that her father (now deceased) had had pinpoint

\begin{tabular}{|c|c|c|c|c|c|c|c|}
\hline & nily member & Sex & Age & $\begin{array}{l}\text { Darkness } \\
\text { diameter }(\mathrm{mm})\end{array}$ & $\begin{array}{l}\text { Light reflex } \\
\text { amplitude (mm) }\end{array}$ & $\begin{array}{l}\text { Near reflex } \\
\text { amplitude }(\mathrm{mm})\end{array}$ & Condition \\
\hline \multirow[t]{14}{*}{ A } & 1.1 & $\mathrm{~F}$ & 97 & $2.5^{*}$ & & & $N$ \\
\hline & II. 1 & M & 75 & 5.2 & 1.7 & 0.7 & $N$ \\
\hline & II.2 & $\mathrm{F}$ & 65 & 5.6 & 2.2 & 1.6 & See text \\
\hline & 11.3 & M & 60 & 6.9 & 2.3 & 2.0 & $N$ \\
\hline & II. 4 & $\mathrm{~F}$ & 58 & 5.4 & 2.5 & 0.8 & $\mathrm{~N}$ \\
\hline & III. 1 & M & 41 & 6.9 & 2.0 & 2.0 & $\mathrm{~N}$ \\
\hline & III. 2 & $M$ & 39 & 7.4 & 2.1 & & $\mathrm{~N}$ \\
\hline & III. 3 & $\mathrm{~F}$ & 37 & $3.9^{*}$ & & & $\mathrm{~N}$ \\
\hline & III. 4 & $\mathrm{~F}$ & 39 & 5.4 & 2.2 & 1.4 & $\mathrm{~N}$ \\
\hline & III.5 & M & 35 & $1.1^{*}$ & & & Microcoria \\
\hline & III.6 & $\mathrm{F}$ & 39 & 5.8 & 2.2 & 1.0 & $\mathrm{~N}$ \\
\hline & IV.1 & M & 8 & 8.1 & 2.6 & & $\mathrm{~N}$ \\
\hline & IV.2 & M & 8 & $1.8^{*}$ & & & Microcoria \\
\hline & IV. 3 & $\mathrm{~F}$ & 2 & 5.2 & 1.8 & & $\mathrm{~N}$ \\
\hline \multirow[t]{7}{*}{ B } & 11.1 & $\mathrm{~F}$ & 54 & 6.4 & 1.8 & 1.5 & $\mathrm{~N}$ \\
\hline & II.2 & $\mathrm{F}$ & 65 & $2.4^{*}$ & & & Microcoria \\
\hline & 11.3 & M & 59 & 6.7 & 2.1 & 1.3 & $\mathrm{~N}$ \\
\hline & III. 1 & M & 36 & 6.8 & 2.8 & 1.3 & $N$ \\
\hline & III.2 & $\mathrm{F}$ & 31 & $2.5^{*}$ & & & Microcoria \\
\hline & IV.1 & $\mathrm{F}$ & 13 & 4.6 & 1.4 & & Miosis \\
\hline & IV. 2 & $\mathrm{~F}$ & 10 & 7.3 & 2.9 & 2.2 & $\mathrm{~N}$ \\
\hline
\end{tabular}



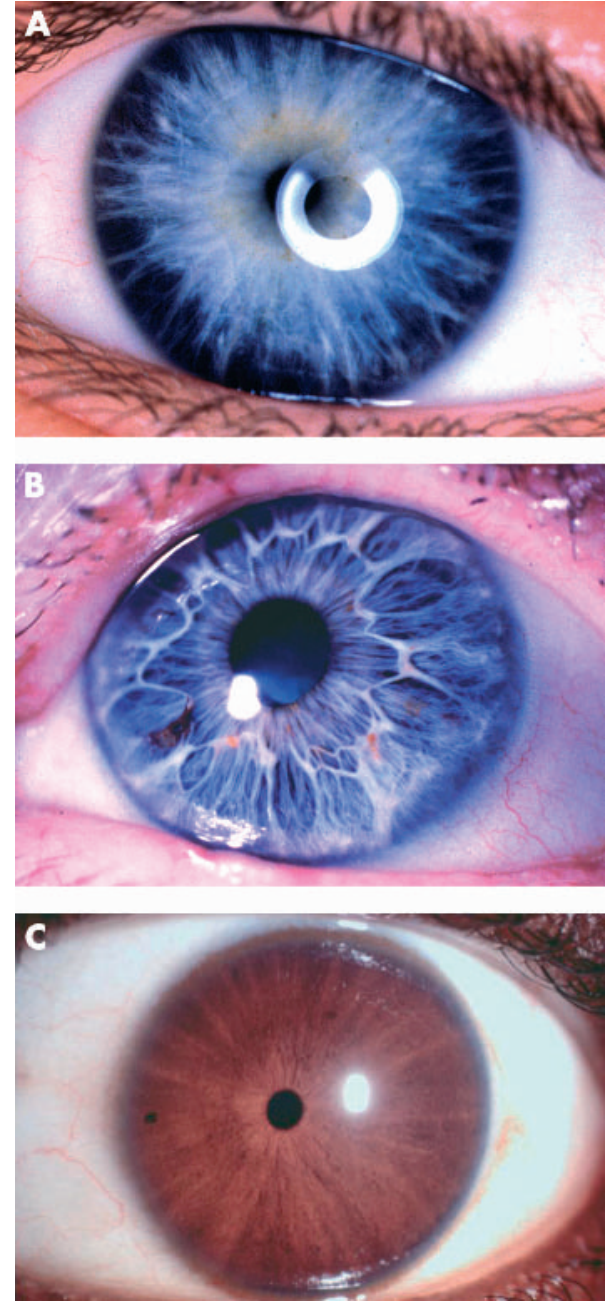

Figure 3 Colour photos of the iris appearances in affected family members. (A, B) Subjects IV.2 and II.2 of family A (respectively). (C) Subject III. 2 of family $B$.

pupils all his life. All other family members studied had normal pupils.

\section{Genetics}

Family A shows evidence of fully penetrant autosomal dominant inheritance with male to male transmission. There is no phenotype difference segregating with sex. Haplotype analysis (fig 4) showed that the 4_11_18 9 5 haplotype (white bar) was seen in two affected individuals but does not segregate in the third (except the 5 allele of D13S158 which recombines). The 4_11_18 9 5 haplotype was also inherited in two unaffected individuals. These data suggest that in this family the gene locus is not within the chromosome $13 \mathrm{q} 31-\mathrm{q} 32$ region.

\section{Family B}

The proband (III.2) had abnormally small pupils which reacted briskly to light and a near effort. A drop of tropicamide $1 \%$ dilated both pupils by $0.65 \mathrm{~mm}$, whereas phenylephrine $10 \%$ dilated the pupils by $1.20 \mathrm{~mm}$ (RE) and $1.25 \mathrm{~mm}$ (LE). Pupil diameters 30 minutes after instillation of both $1 \%$ tropicamide and $10 \%$ phenylephrine were $4.90 \mathrm{~mm}$ and $4.80 \mathrm{~mm}$ (RE and LE respectively), still below the lower limit of the normal range in age matched controls $(5.45 \mathrm{~mm})$. Slit lamp examination showed smooth, featureless almost "velvety" iris stroma lacking normal crypts and trabecular structure (fig 3C). Her anterior segments were otherwise unremarkable with normal intraocular pressures. With myopic corrections she had normal acuities and visual fields.

The proband's mother (II.2) had similar microcoria and iris stromal abnormalities, and reported that her father (now deceased) had had pinpoint pupils all of his adult life. The proband's elder daughter (IV.1) had pupil diameters below the normal limit $(<5.8 \mathrm{~mm}$ ) which reacted normally to light. Redilatation times following standard light responses lay within the normal range $\left(\mathrm{T}_{3 / 4}=2.3\right.$ seconds) and both pupils showed reflex dilatation to psychic stimulation (sudden loud noise). All other family members studied had normal pupils. Both affected adults (II.2 and III.2) stated that their pupils had not always been so small, and old photographs (taken in daylight) confirmed that as teenagers they had large pupils.

\section{Genetics}

In family B the exact mode of inheritance is uncertain, but is probably autosomal dominant. In theory it could be X linked, but the proband's grandfather did produce at least one unaffected daughter, making this mode of transmission unlikely. Haplotype analysis showed the 3_11_10_8_2 haplotype (white bar) in two affected individuals; in the third (IV.1), alleles 8_2 of D13S159 and D13S158 have recombined giving this individual only a small part of the genetically linked region. These results rule out the region between D13S156 and D13S265 but the region between D13S265 (68.73 cM) and D13S158 (84.87 cM) could harbour the gene.

\section{DISCUSSION}

A number of mechanisms might account for the microcoria. Firstly, overaction of the sphincter muscle: this seems unlikely as all affected pupils showed normal light and near responses (contrast with the spastic miosis induced by pilocarpine), and dilated less well with tropicamide than with phenylephrine. Secondly, local changes within the iris might mechanically restrict the pupil: however brisk light and near reactions would not be expected. Thirdly, a central disturbance to the balance between sympathetic and parasympathetic tone: the strikingly abnormal appearance of the irides on biomicroscopy could only fit with this "central" hypothesis if one assumes these changes are secondary.

Finally, underaction of the dilator muscle: the normal redilatation times and responses to psychic stimulation in subject II.2 (family B) imply that at least in her case sympathetic innervation was normal. We were however impressed by the apparent dilator muscle hypoplasia seen in all affected members of both pedigrees, suggesting that even in family B, where the onset of the condition is delayed, familial microcoria may be a primary dystrophy of the iris dilator muscle. This accords with other published histological evidence. ${ }^{11-14}$ The small pupil size with preserved reactions imply that this dystrophy affects active contraction of the muscle without either impairing muscle relaxation or mechanically restricting the pupil.

There are a number of features of these microcoria that are shared by both of our families and by other pedigrees reported in the literature, namely the autosomal dominant mode of inheritance, the normal responses to light and accommodation, the isolated nature of this anomaly, and its minimal impact on visual function. Closer inspection however reveals both genotypic and phenotypic heterogeneity. Haplotype analysis on family A suggests that their genetic defect does not lie in the same locus as the French pedigree. ${ }^{17}$ The phenotype is markedly different in these two families, both in the appearance of the iris (compare fig 3A and 3C) and the age at onset. Comparison of the data from both pedigrees leads us to the conclusion that familial microcoria 


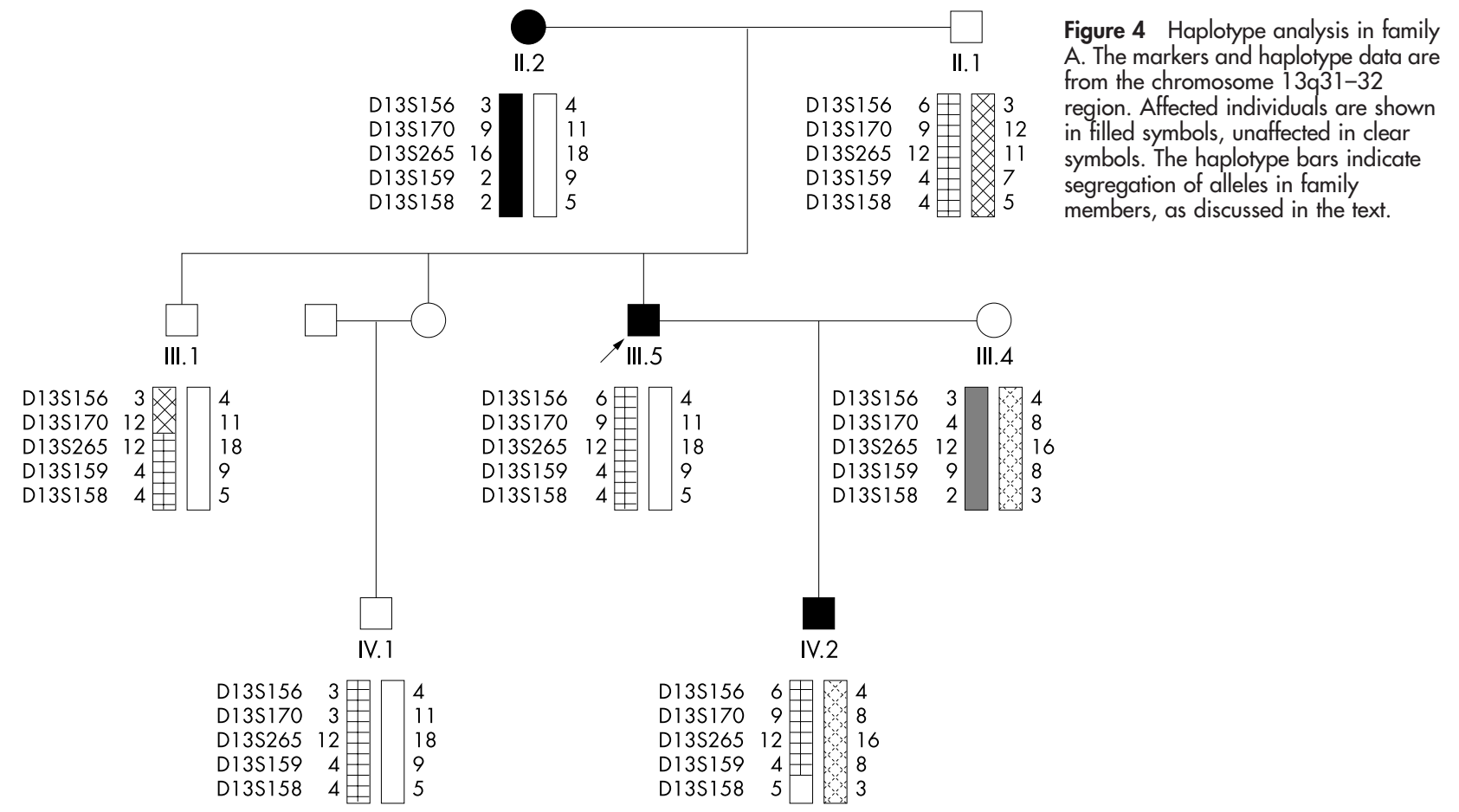

is not a single entity but the result of heterogenous genetic abnormalities, possibly acting via different mechanisms to produce a pupil anomaly which may not even be apparent at birth. The recognition of this rare but benign condition is important in order to avoid inappropriate investigation,

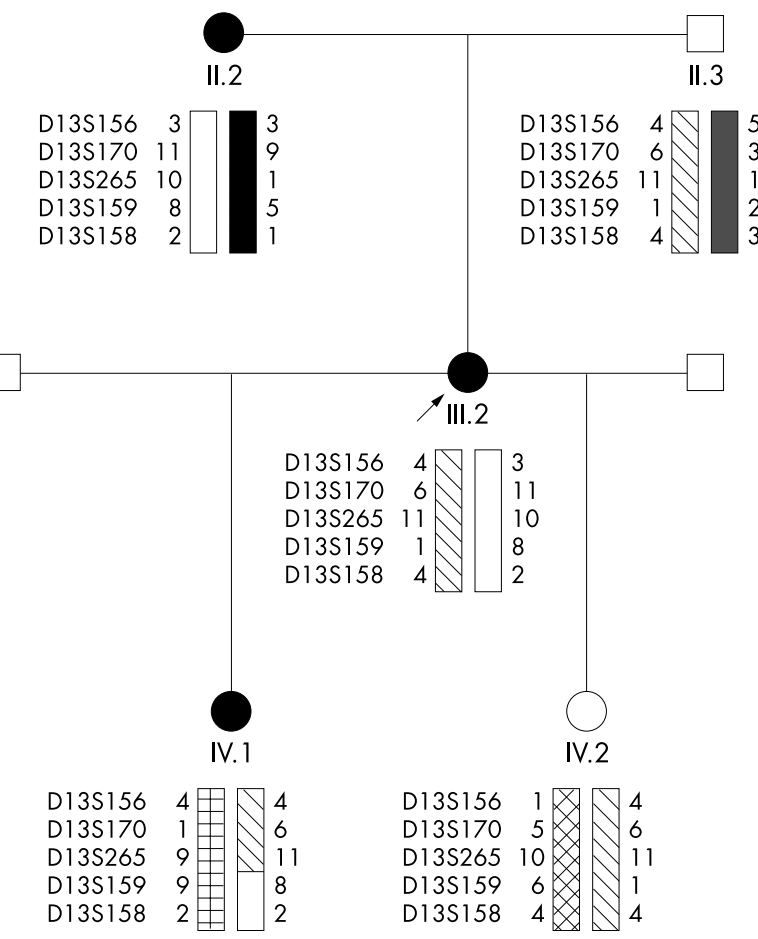

Figure 5 Haplotype analysis in family B. The markers and haplotype data are from the chromosome 13q31-32 region. Affected individuals are shown in filled symbols, unaffected in clear symbols. The haplotype bars indicate segregation of alleles in family members, as discussed in the text. particularly in pedigrees like family $\mathrm{B}$ where the pupil abnormality appears some time after birth.

\section{Authors' affiliations}

F D Bremner, S E Smith, Department of Neuro-ophthalmology, National Hospital for Neurology \& Neurosurgery, London, UK

H Houlden, Department of Neurogenetics, Institute of Neurology, London, UK

Correspondence to: Fion Bremner, Department of Neuroophthalmology (Box 142), National Hospital for Neurology \& Neurosurgery, Queen Square, London WCIN 3BG, UK; fionbremner@doctors.org.uk

Accepted for publication 11 August 2003

\section{REFERENCES}

1 Holth S, Berner O. Congenital miosis or pinhole pupils owing to developmental faults of the dilatator muscle. Br J Ophthalmol 1923;7:401-19.

2 Van Leeuwen MA. La microcorie congenitale hereditaire. Bull Soc Belge Ophtalmol 1949;91:118-36.

3 Ardouin M, Urvoy M, Lefranc J. Microcorie congénitale. Bulletins et Memoires de la Société Française d'Ophtalmologie 1964;77:356-63.

4 Polomeno RC, Milot J. Congenital miosis. Canad J Ophth 1979;14:43-6.

5 Tawara A, Inomata H. Familial cases of congenital microcoria associated with late onset congenital glaucoma and goniodysgenesis. Jap J Ophthalmol 1983;27:63-72.

6 Mazzeo V, Gaiba G, Rossi A. Hereditary cases of congenital microcoria and goniodysgenesis. Ophthal Paediatr Genet 1986;7:121-5.

7 Meire FM, Delleman JW. Autosomal dominant congenital miosis with megalocornea. Ophthal Paediat Genet 1992;13:123-9.

8 Saxena S, Saxena RC. Congenital microcoria: a study in three generations. Indian J Ophthalmol 1993;41:130-2.

9 Toulemont PJ, Urvoy M, Coscas G, et al. Association of congenital microcoria with myopia and glaucoma. Ophthalmol 1995; 102:193-8.

10 Ainsworth JR, Morton JE, Good P, et al. Micro syndrome in Muslim Pakistani children. Ophthalmology 2001;108:491-7.

11 Simpson WAC, Parsons MA. The ultrastructural pathological features of congenital microcoria. Arch Ophthal 1989;107:99-102.

12 Coulon G, Delbosc B, Jeffredo Y, et al. La microcorie congenitale: une observation avec etude histopathologique. J Fr Ophtal 1986;9:35-9.

13 Butler JM, Raviola G, Miller CD, et al. Fine structural defects in a case of congenital microcoria. Graefes Arch Clin Exp Ophthal 1989;227:88-94. 
14 Pietropaolo A Corvino C DeBlasi A et al Congenital microcoria: case report and histological study. J Pediatr Ophthalmol Strabismus 1998;35:125-7.

15 Veirs ER, Brown W. Congenital miosis associated with a narrow angle of the anterior chamber and abnormally placed iris tissue. Arch Ophth $1961 ; 65: 59-60$.

16 Lambert SR, Amaya L, Taylor D. Congenital idiopathic microcoria. Am J Ophthal 1988;106:590-4.
17 Rouillac $C$, Roche $O$ Marchant $D$, et al. Mapping of a congenital microcoria locus to 13q31-q32. Am J Hum Genet 1998;62:1117-22.

18 Smith SA, Smith SE. Bilateral Horner's syndrome: detection and occurrence. J Neurol Neurosurg Psychiat 1999;66:48-51.

19 Anderson DR. The normal visual field. In Perimetry with and without automation, 2nd edition. St Louis, MO: CV Mosby Company 1987:80-81.

\section{Video reports}

To view the video reports in full visit our website www. bjophthalmol.com and click on the link to video reports.

- Laser photocoagulation for posterior segment intraocular parasites. T Prabriputaloong, S Asawaphureekorn

- Feeder vessel treatment with high speed ICG angiography. D Stanescu-Segall, $G$ Coscas, F Coscas, G Soubrone

- Endoscopy to aid anterior segment surgery. J E Maore, A Sharma

- Penetrating ocular injury due to a fish hook: surgical removal. SDM Chen, D Chiu, C K Patel

- Retinal ganglion cell axon response to guidance molecules S F Oster, D W Sretavan

- Marin-Amat syndrome A Jogiya, C Sandy

- Excision of subcutaneous dirofilariasis of the eyelid D Mallick, T P Ittyerah

- Thixotropy: a novel explanation for the cause of lagophthalmos after peripheral facial nerve palsy. M Aramideh, J H T M Koelman, P P Devriese, F VanderWerf, J D Speelman

- Surgical revision of leaking filtering blebs with an autologous conjunctival graft. K Taherian, A Azuara-Blanco

- Dipetalonema reconditum in the human eye. THuynh, J Thean, R Maini

- Evaluation of leucocyte dynamics in mouse retinal circulation with scanning laser ophthalmoscopy. H XU, A Manivannan, G Daniels, J Liversidge, P F Sharp, JV Forrester, I J Crane

- An intraocular steroid delivery system for cataract surgery. D F Chang

- Pearls for implanting the Staar toric IOL. D F Chang

- Capsule staining and mature cataracts: a comparison of indocyanine green and trypan blue dyes. D F Chang 